\title{
Gene expression time-series analysis of Camptothecin effects in U87-MG and DBTRG-05 glioblastoma cell lines Elena Morandi ${ }^{1}$, Cinzia Severini ${ }^{1}$, Daniele Querciolii ${ }^{1}$, Giovanni D'Ario², Stefania Perdichizzi ${ }^{3}$, Miriam Capri ${ }^{4}$, Giovanna Farruggia ${ }^{5}$, Maria Grazia Mascolo1, Wolfango Horn ${ }^{1}$, Monica Vaccari ${ }^{1}$, Roberto Serra ${ }^{6}$, Annamaria Colacci ${ }^{1}$ and Paola Silingardi*1
}

Address: ${ }^{1}$ Excellence Environmental Carcinogenesis, Lab. Mater, Environmental Protection and Health Prevention Agency - Emilia-Romagna Region (ER-EPA), Viale Filopanti 22, 40126, Bologna County, Italy, ${ }^{2}$ The FIRC Institute of Molecular Oncology Foundation, Via Adamello 16, 20139, Milan, Italy, ${ }^{3}$ Department of Experimental Pathology-Cancer Research Section, University of Bologna, Viale Filopanti 22, 40126, Bologna, Italy, ${ }^{4} \mathrm{CIG}$, Interdepartmental Research Centre "L. Galvani", University of Bologna, Via S. Giacomo 12, 40126, Bologna, Italy, ${ }^{5}$ Department of Biochemistry, University of Bologna, Via Irnerio 48, 40126, Bologna, Italy and ${ }^{6}$ Department of Social, Cognitive and Quantitative Sciences, University of Modena and Reggio Emilia, Via Allegri 9, Reggio Emilia, Italy

Email: Elena Morandi - emorandi@arpa.emr.it; Cinzia Severini - cseverini@arpa.emr.it; Daniele Quercioli - querciol@yahoo.it; Giovanni D'Ario - Giovanni.dario@ifom-ieo-campus.it; Stefania Perdichizzi - mcalab@istbiotech.it; Miriam Capri - miriam.capri@unibo.it; Giovanna Farruggia - giovanna.farruggia@unibo.it; Maria Grazia Mascolo - mcalab@unibo.it; Wolfango Horn - w.horn@istbiotech.it; Monica Vaccari - m.vaccari@istbiotech.it; Roberto Serra - roberto.serra@unimore.it; Annamaria Colacci - a.colacci@istbiotech.it; Paola Silingardi* - p.silingardi@istbiotech.it

* Corresponding author

Published: II August 2008

Molecular Cancer 2008, 7:66 doi:10.1186/1476-4598-7-66
Received: 28 January 2008

Accepted: II August 2008

This article is available from: http://www.molecular-cancer.com/content/7/1/66

(c) 2008 Morandi et al; licensee BioMed Central Ltd.

This is an Open Access article distributed under the terms of the Creative Commons Attribution License (http://creativecommons.org/licenses/by/2.0), which permits unrestricted use, distribution, and reproduction in any medium, provided the original work is properly cited.

\begin{abstract}
Background: The clinical efficacy of camptothecin (CPT), a drug specifically targeting topoisomerase I (Topol), is under evaluation for the treatment of malignant gliomas. Due to the high unresponsiveness of these tumours to chemotherapy, it would be very important to study the signalling network that drives camptothecin outcome in this type of cancer cells. To address this issue, we had previously compared the expression profile of human U87-MG glioblastoma cells with that of a CPT-resistant counterpart, giving evidence that the development of a robust inflammatory response was the main transcriptional effect associated with CPT resistance.

Here we report time-related changes and cell line specific patterns of gene expression after CPT treatment by using two p53 wild-type glioblastoma cell lines, U87-MG and DBTRG-05, with different sensitivities to Topol inhibition.

Results: First, we demonstrated that CPT treatment brings the two cell lines to completely different outcomes: accelerated senescence in U87-MG and apoptosis in DBTRG-05 cells. Then, to understand the different susceptibility to CPT, we used oligo-microarray to identify the genes whose expression was regulated during a time-course treatment, ranging from $2 \mathrm{~h}$ to $72 \mathrm{~h}$. The statistical analysis of microarray data by MAANOVA (MicroArray ANalysis Of VAriance) showed much less modulated genes in apoptotic DBTRG-05 cells (155) with respect to the senescent U87MG cells (3168), where the number of down-regulated genes largely exceeded that of the upregulated ones $(80 \%$ vs. $20 \%)$. Despite this great difference, the two data-sets showed a large overlapping $(60 \%$ circa) mainly due to the expression of early stress responsive genes. The use of
\end{abstract}


High-Throughput GoMINER and EASE tools, for functional analysis of significantly enriched GO terms, highlighted common cellular processes and showed that U87-MG and DBTRG-05 cells shared many GO terms, which are related to the down-regulation of cell cycle and mitosis and to the up-regulation of cell growth inhibition and DNA damage.

Furthermore, the down-regulation of MYC and DPI genes, which act as key transcription factors in cell growth control, together with the inhibition of BUBI, BUB3 and MAD2 mRNAs, which are known to be involved in the spindle checkpoint pathway, were specifically associated with the execution of senescence in U87-MG cells and addressed as critical factors that could drive the choice between different CPT-inducible effectors programs. In U87-MG cells we also found inflammation response and ILI-beta induction, as late transcriptional effects of Topo I treatment but these changes were only partially involved in the senescence development, as shown by ILIbeta gene silencing.

Conclusion: By comparing the transcription profile of two glioblastoma cell lines treated with camptothecin, we were able to identify the common cellular pathways activated upon Topo I inhibition. Moreover, our results helped in identifying some key genes whose expression seemed to be associated with the execution of senescence or apoptosis in U87-MG and DBTRG-05 cells, respectively.

\section{Background}

Camptothecin, a naturally occurring cytotoxic alkaloid, and its water-soluble derivatives belong to a family of antineoplastic agents specifically targeting topoisomerase I. They exert their main S-phase cytotoxic activity through the accumulation of DNA double-strand breaks, originating from the collision between the replication fork and the ternary complex TopoI-CPT-DNA [1,2]. In general, CPT treatment arrests cells in G2 phase and can trigger rapid apoptosis in some cell types [3]. However, in the presence of low CPT doses and limited DNA damage extension, the induction of a senescence-like-phenotype (SLP) was observed [4-6]

Most of the molecular events elicited by CPT deal with stress response and cell survival signaling pathways activated by DNA damage $[7,8]$. Beside the ATM/Chk2 DNA damage checkpoint pathway, the ATR-Chk1 response has recently been described to play a predominant role in the response to Topol inhibition [9]. Furthermore, in many cellular systems, CPT was able to activate NF-kB, a key transcriptional factor that regulates the survival response induced by many chemotherapeutics $[10,11]$. All these pathways clearly converge on the transcriptional machinery, thus affecting the transcriptome in a relevant manner. For this reason, a global analysis of gene expression modulation by microarray could produce new insights into the complexity of TopoI poisons stress responses [12].

The transcriptional profile of CPT effects has been determined in HCT116 synchronized human colon cancer cells, in a time-series study, by treating cells with relatively low (20 nM) and high (1000 nM) drug concentrations [13]. A microarray analysis was also reported for HeLa cells and ML-2 myeloid leukemia cells, in a single-time treatment experiment with a CPT concentration able to induce apoptosis $[3,14]$. Recently, the changes in gene expression, following the short-term exposure of HL60 cells, to SN-38, the active metabolite of camptothecin, were compared with those derived from the peripheral blasts of patients with acute and chronic myeloid leukemia, that had undergone a therapy with a single dose of Irinotecan (CPT-11), a water soluble derivative of camptothecin [15]. This study showed a number of genes whose expression was commonly affected by CPT-11 both in vitro and in vivo. In addition, Reinhold et al. investigated the mechanism of CPT-11 resistance in DU145 human prostate cancer cells, by using microarray technology and analysis [16].

All these studies were useful to generate new hypothesis on the mechanisms of Topo 1 inhibition that were unpredictable on the basis of the known properties of the drug.

As the use of camptothecins is under evaluation for the treatment of malignant gliomas $[17,18]$, we previously analysed the transcriptional profile of CPT resistant U87MG glioma cells, obtained from repeated exposures of the parental cell line to a high CPT concentration [19]. Our results had demonstrated that many of the most up-regulated genes trigger cellular mechanisms, like inflammatory response and angiogenesis, that can negatively impact upon chemotherapy efficacy.

To clarify the effects of TopoI inhibition in glioblastoma cells, in the present study we first checked the sensitivity of two human glioblastoma cell lines, U87-MG and DBTRG-05, to CPT and, then, we characterized the CPT- 
induced transcriptional response during a short timecourse treatment ranging from 2 to 72 hours, by using high density oligonucleotide (60-mer) array technology. Although the two cell lines are both representative of high grade glioblastoma and are considered p53 wild-type, DBTRG-05 cells underwent mainly apoptosis while U87MG cells developed a senescence-like phenotype.

The expression profiling showed the common biological processes that are modulated by TopoI in both cell lines and identified specific gene networks linked to the development of senescence in U87-MG cells. Apoptosis and senescence are considered two alternative mechanisms of the chemotherapy-induced tumor repression. Many questions, however, still, remain open about the effective role that accelerated senescence has in a clinical setting, mainly due to its potential detrimental effects [20-22]. Therefore, the transcriptional analysis of the mechanisms underlying the execution of two distinct camptothecin effectors programs could help in better understanding the final outcome of Topol poisoning.

\section{Results}

CPT treatment promotes a senescence-like phenotype in U87-MG cells but induces apoptosis in DBTRG-05 cells

The effect of CPT on glioblastoma cells was first assessed by the crystal violet growth inhibition assay. The doseresponse curves from a 72-hour treatment with different concentrations of CPT, were used to calculate the GI50 values (50\% Growth Inhibition). As shown in Figure 1A, DBTRG-05 cells are more sensitive to TopoI inhibition, being the GI50 value five times lower in this cell line $(0.018 \mu \mathrm{M})$ than in U87-MG cells $(0.09 \mu \mathrm{M})$.

The ability of CPT to induce apoptosis was then analyzed in both cell lines, by using the Annexin-V method (Figure $1 \mathrm{~B}$ ). Even if the positive control (actinomycin D plus TNF alpha) triggered a similar response in the two cell lines, only DBTRG-05 cells showed a significant induction of apoptosis, after 24 h-treatment with CPT, even at the lower assayed dose of $0.05 \mu \mathrm{M}$. U87-MG cells remained substantially refractory to apoptosis, at all the assayed concentrations except for a slight effect (13.9\%) detected at the dose $5 \mu \mathrm{M}$ CPT. These data were further confirmed by using CPT at the concentrations of $0.2 \mu \mathrm{M}$ and $1 \mu \mathrm{M}$, for DBTRG-05 and U87-MG cells, respectively (Figure 2). These doses were extrapolated from the linear regression curves, as showed in Figure 1A, to give a similar growth inhibitory effect, on both cell lines, with a maximum effect (100\% growth inhibition) after 72-hours treatment. Camptothecin was able to induce a significant increase of apoptosis in DBTRG-05 cells, after 24 and 72 hours treatments, while no up-regulation of annexin- $\mathrm{V}$ positive cells was observed in the U87-MG population (Figure 2A and 2B).
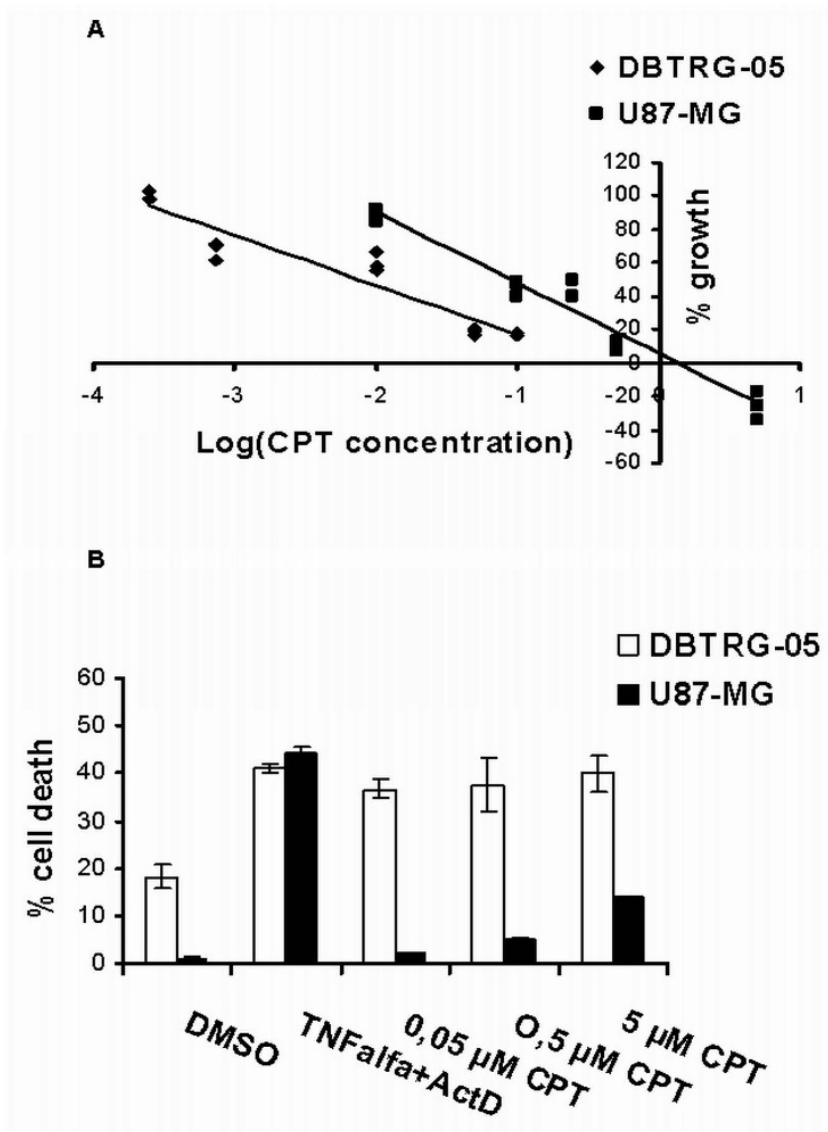

Figure I

CPT-induced acute citotoxicity and apoptosis. A. Dose-response analysis of CPT effects on U87-MG and DBTRG-05 cells. On Y-axis the percentage of growth, calculated according to the protocol used by the National Cancer Institute, is reported. The GI50 values for both cell lines were calculated by linear regression analysis of the log (dose/ effect) curve. B. Annexin- $V$ apoptosis assay was performed after a 24-h treatment with 0.5 and $5 \mu \mathrm{M}$ CPT. DMSO and TNF-alpha plus actinomycin D were used as negative and positive controls, respectively. Each data point is the average of three independent experiments; bars, standard errors.

The cell cycle distribution of the two cell lines, in response to CPT treatment, was then assessed by using flow cytometry after pulse-BrdU incorporation. DNA Topol inhibition caused almost similar effects on the two cell lines, during a time-course treatment ranging from 2 to 72 hours (Figure 3A). Both U87-MG and DBTRG-05 cells underwent a considerable G2/M arrest (U87 72 h/U87 NT: $27.9 \% / 19.6 \%$; DBTRG 72 h/DBTRG NT:33.8\%/ $12.6 \%$ ) with a concomitant increase in the percentage of non-cycling S-phase cells at all the tested time intervals. A slight increase in the population of cells with a DNA content above $4 \mathrm{~N}(6.6 \%)$ was observed in U87-MG cells 72 hours after CPT exposure. The apparent recovery of BrdU- 
A

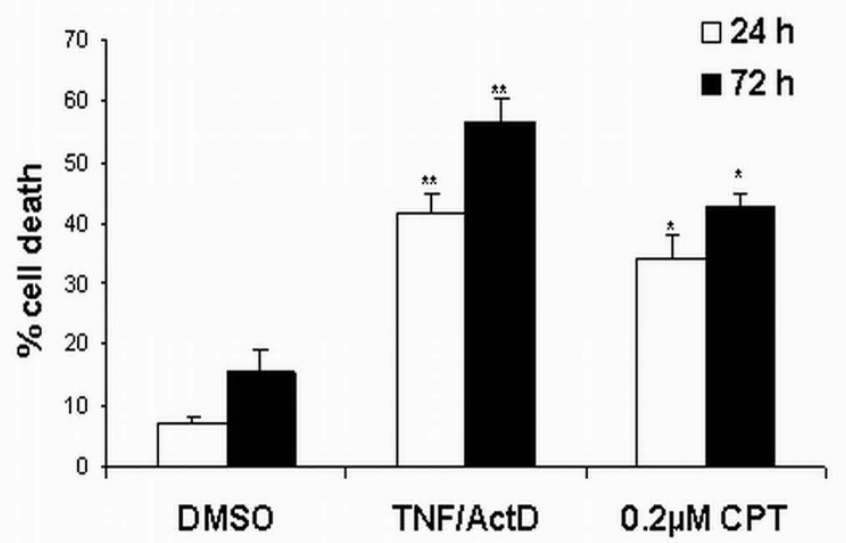

B

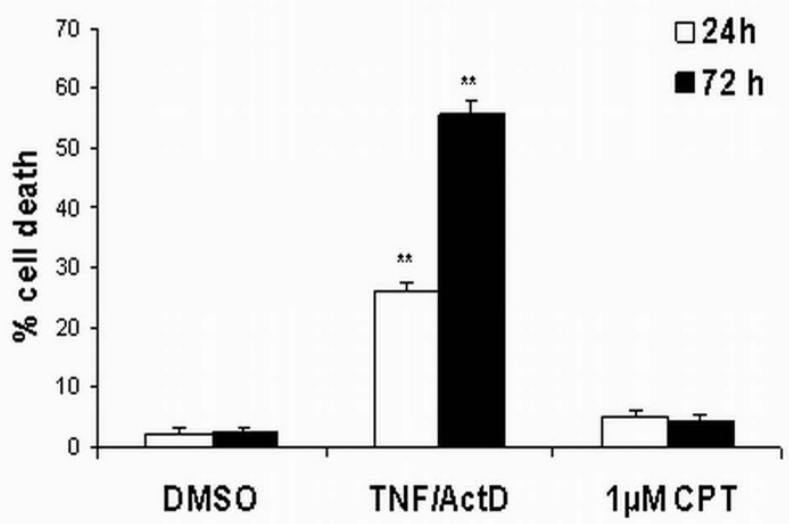

Figure 2

Apoptotic response of DBTRG-05 and U87-MG cells exposed to CPT working concentrations. A. Percentages of Annexin-V positive DBTRG-05 cells treated for 24 and 72 hours with $0.2 \mu$ M CPT. * $p<0.05$, Student's t-test. ** $p<0.01$, Student's t-test. B. Percentages of Annexin-V positive U87-MG cells treated for 24 and 72 hours with I $\mu$ M CPT; bars, standard errors. ** $p<0.01$, Student's t-test.

positive cells, that we observed after $16 \mathrm{~h}$ and $24 \mathrm{~h}$ from the treatments, was associated to the aspecific fluorescence caused by CPT, as shown by the shift to the right of the $16 \mathrm{~h}$ - and $24 \mathrm{~h}-\mathrm{S}$ phase monoparametric curves and by the microscope analysis of cells under fluorescence (data not shown). The FACS data, together with the observation that U87-MG cells became flatter with enlarged nuclei in response to CPT, suggested that TopoI inhibition could elicit a senescence-like phenotype in this cell line. We then investigated the expression of senescence-associated betagalactosidase activity (SA- $\beta$-gal) and showed that U87MG cells stained significantly positive for SA- $\beta$-Gal, after a 72-hours treatment with $1 \mu \mathrm{M}$ CPT (Figure $3 \mathrm{~B}$ ).

\section{Microarray analysis of time course treatment with CPT}

To better characterize the molecular mechanisms underlying the response to CPT, we next analyzed the changes in gene expression, during a time-course treatment ranging from 2 to 72 hours, with the drug concentrations of 0.2 $\mu \mathrm{M}$ for DBTRG-05 cells and $1 \mu \mathrm{M}$ for U87-MG cells. For this purpose, we used high density oligonucleotide (60 mer) microarrays containing more than 17.000 unique probes (Human1A oligo microarray, G4110A, Agilent Technologies, Palo Alto, CA).

The statistical analysis of the two time-series data sets was performed with MAANOVA, a collection of functions for the statistical analysis of gene expression data from twocolor cDNA microarray experiments that is implemented as an add-on package for the freely available and widely used statistical language/software R (see details in materials and methods) [23].
The lists of differentially expressed genes were numerically completely different. Applying a p-value threshold of 0.01 and 0.05 for U87-MG and DBTRG-05 cells respectively, the total number of differentially expressed genes was 3168 in the U87- and only 155 in the case of the DBTRG05. To facilitate the comparison between the two datasets, we restricted the analysis to those genes that reached a $\log _{2}$ (expression ratio) value above 1.5 , at least in one of the six time-series data points. By doing that, we reduced the overall number of differentially expressed genes to 713 for U87-MG cells and to 92 for DBTRG cells (see Additional files 1 and 2 to retrieve the complete lists of genes returned from MAANOVA analysis and the filtering process). Based on the time dependent expression profile, we defined the up- and down-regulated genes within the two data sets. Interestingly, this analysis, that is summarized in the Venn diagrams reported in Figure 4, demonstrated that most of the genes, whose expression was affected by the treatment with CPT, were indeed downregulated (almost $80 \%$ ) in U87-MG cells, while a substantial balance between up- and down-regulation was observed in the DBTRG-05. Despite this difference, the two data-sets were largely overlapping, being more than the $60 \%$ of the genes found in DBTRG-05 cells also represented in the U87-MG population. In Table 1 and Table 2, we reported the lists of the common up-regulated genes and the down-regulated ones, respectively. Only four genes (AREG, MYC, MIG-6 and GEM) showed a different time-dependent expression profile between the two datasets (Figure 5). Indeed, CPT treatment induced the expression of these genes in DBTRG-05 cells while repressed them in U87-MG cells. For selected time-points, three of 

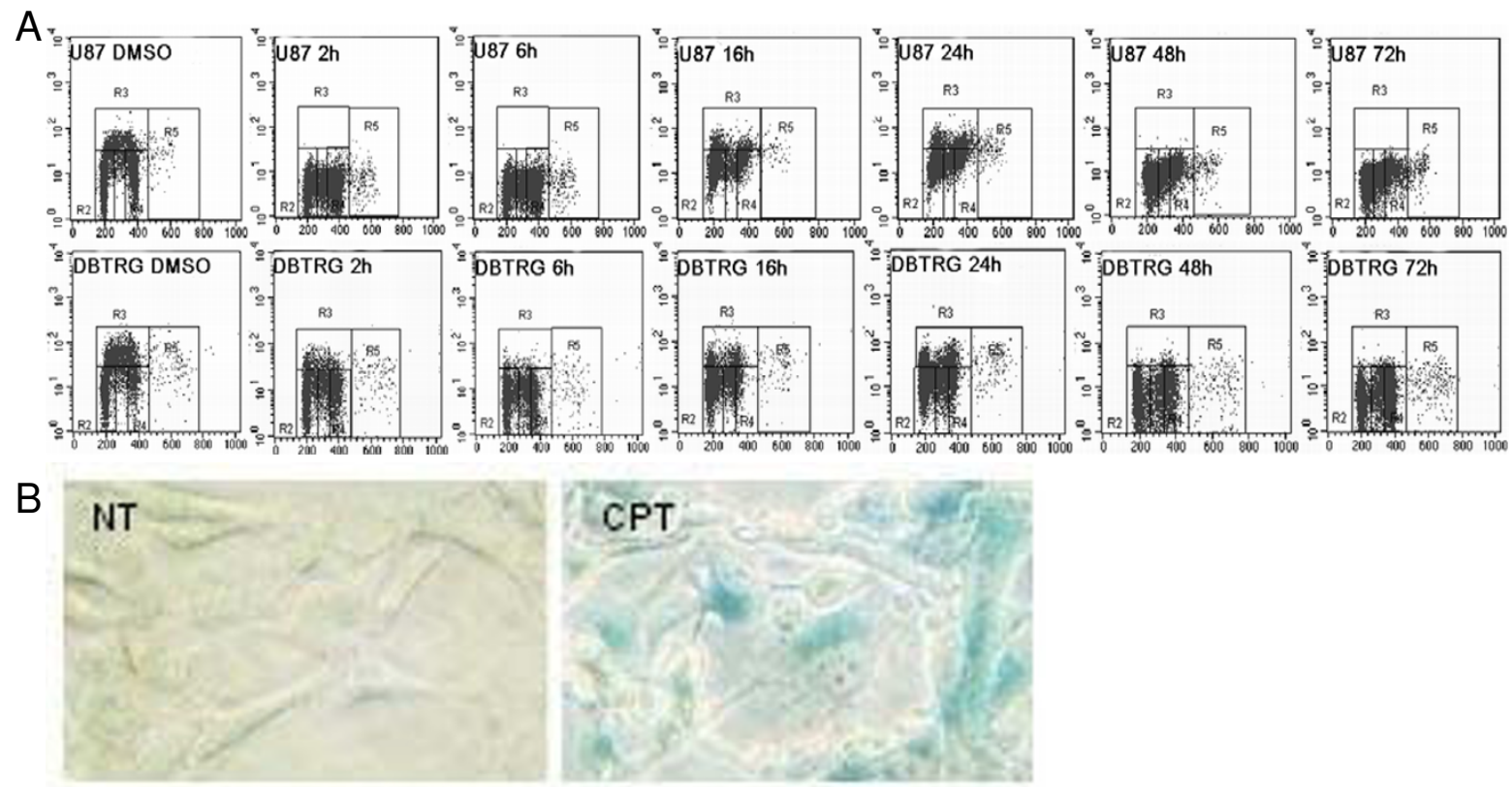

\begin{abstract}
Figure 3
BrdU Flow cytometry assay of U87-MG and DBTRG-05 cells exposed to CPT and SA- $\beta$ Gal staining in treated U87-MG cells. A. Time dependent changes in DNA content following treatment, from 2 to 72 hours, of U87-MG and DBTRG-05 cells with I $\mu$ M and $0.2 \mu$ M CPT, respectively. DMSO: solvent control B. SA- $\beta$ Gal staining of CPT-exposed U87MG cells (CPT) versus control (NT). For this purpose, a $72 \mathrm{~h}$ treatment with I $\mu \mathrm{M}$ CPT was performed. Counts were made on three random fields of about 100 cells.
\end{abstract}

these genes (AREG, MYC, GEM) were chosen to be confirmed through a semi-quantitative RT-PCR analysis, together with other genes (CDKN1A, TXNIP, GADD45A, EREG) known to be CPT transcriptional targets (Figure 6). Taking into account that we used a semi-quantitative approach, we found overlapping results between two techniques except for AREG in U87- and EREG in DBTRG05 cells whose over-expression was undetectable in microarray.

\section{Functional analysis of microarray data through High- Throughput GoMINER and EASE}

To have a general picture of the most affected biological processes during the time-course treatment, as defined by Gene Ontology annotation, first we used the HighThroughput GoMINER analysis tool http://dis cover.nci.nih.gov/gominer/htgm.jsp [24]. This package allows the automatic analysis of multiple microarrays and then integrates the results, across all of them, to find the GO categories that were significantly over-represented. To reach this goal the program first estimates the p-value using Fisher's exact test and then corrects the p-values for the multiple comparisons by estimating the FDR (False Discovery Rate).
For each time point, we defined as up-regulated or downregulated those genes having a $\log _{2}$ (expression ratio) above 1.5. The results were represented as clustered image maps (CIM), where the enriched GO categories (FDR < 0.05) are hierarchically clustered (Euclidean distance, average linkage clustering) against time either for the upand the down- regulated genes. (Additional file 3, 4 and 5).

Two main blocks of biological processes were down-regulated in both cell lines treated with CPT. The first was DNA metabolism (GO:0006260), with all the correlated molecular mechanisms regulating dNTPs metabolism, DNA replication and repair, and the second was mitosis and all the events regarding the regulation of $M$-phase (GO:0000087) as well as the formation and maintenance of the spindle (GO:0007051_spindle_organization _and_biogenesis). Most of the above biological processes converged into the main down-regulated process, that was cell cycle (GO:0007049). In Table 3, we listed the genes belonging to some of the more representative down-regulated GO categories.

Between the up-regulated GO terms, the response to DNA-damage stimulus (GO:0006974) and cell cycle 
Table I: List of Genes up-regulated following CPT treatment in both U87-MG and DBTRG-05 cells.

\begin{tabular}{|c|c|}
\hline GeneName & Description \\
\hline & DNA-Damage and/or stress-responsive genes \\
\hline ATF3 & Activating transcription factor 3 \\
\hline CDKNIA & Cyclin-dependent kinase inhibitor IA \\
\hline DDIT3 & DNA damage inducible transcript 3 \\
\hline DUSP5 & Dual specificity phosphatase 5 \\
\hline EGRI & Early growth response I \\
\hline EGR3 & Early growth response 3 \\
\hline FDXR & Ferredoxin reductase \\
\hline GADD45A & DNA damage inducible transcript I \\
\hline p53CSV & p53-inducible cell-survival factor \\
\hline PIG3 & tumor protein $p 53$ inducible protein 3 \\
\hline SAT & Spermidine/spermine $\mathrm{NI}$-acetyltransferase \\
\hline TIEG & TGFB inducible early growth response \\
\hline \multirow[t]{2}{*}{ TRIB3 } & tribbles homolog 3 (Drosophila) \\
\hline & miscellaneous \\
\hline GA & Breast cell glutaminase \\
\hline I_I201768 & Protein of unknown function \\
\hline I_928877 & Protein of unknown function \\
\hline I_929113 & Protein with very strong similarity to ribonucleotide reductase induced by $p 53$ (human p53R2) \\
\hline IL8 & Interleukin 8 \\
\hline KLF5 & Kruppel-like factor 5 (intestinal) \\
\hline PPIF & Peptidylprolyl isomerase $F$ \\
\hline SEII & Cyclin-dependent kinase 4-binding protein \\
\hline EDIL3 & EGF-like repeats and discoidin I-like domains 3 \\
\hline
\end{tabular}

arrest (GO:0007050) appeared to be the biological processes that were more significantly affected by CPT in both cell line.

The two data sets were also analyzed by EASE, a publicly available and stand-alone application for use on Windows operating systems [25]. We used EASE to identify the enriched GO-Categories corresponding to "biological processes" in the list of up and down-regulated genes with respect to the whole list of genes of the microarray. In Table 4 we reported only those categories having an EASE score, corrected for multiple comparisons with the Bonferroni method, below 0.05 .

Even if EASE analysis was more restrictive than that of High-Throughput GoMINER (also due to the choice of the stringent Bonferroni correction), it gave "cell cycle" and "DNA metabolism" as common CPT-down-regulated biological processes in the two glioblastoma cell lines.

No significant enriched GO category was found by EASE in the list of up-regulated DBTRG genes whereas in U87MG cells, besides the "negative regulation of cell proliferation", the terms "response to stimulus" and "response to stress" were called as significantly enriched biological processes. Some of the genes involved in the response to stress were also implicated in inflammatory response such as FOS; IL1B; IL8; PRDX5; PROCR and TNFAI.

\section{Role of IL-Ibeta in senescence development}

In apoptotic DBTRG-05 cells we did not find any significant modulation of IL1-beta or other genes involved in inflammation, while IL-1beta over-expression was observed in U87-MG cells, at the latest time points (48 h and $72 \mathrm{~h}$ ) of the time-course.

Taking into account that U87-MG resistance to CPT was previously suggested to be sustained by IL1-beta up-regulation [19], we decided to investigate the role that the late expression of IL-1beta could have in the development of senescence. For this purpose, U87-MG cells were transiently transfected with two different IL-1beta siRNA (IL1B_4_HPsiRNA and IL1B_6_HPsiRNA, Qiagen) and, after one day, treated with $1 \mu \mathrm{M}$ CPT for $72 \mathrm{~h}$. Both siRNAs were able to significantly knock down the expression of IL-1beta, as determined by Real-Time PCR (Figure 7A). The effect of IL-1beta silencing on the development of accelerated senescence was evaluated by measuring the SA- $\beta$-gal activity and the cloning efficiency of transfected cells (Figure 7B and 7C).

\section{Discussion}

We adopted oligo-microarray technology to compare the transcriptional response induced by CPT-dependent DNA damage in two high-grade glioblastoma cell lines. Following TopoI inhibition, apoptosis and senescence were the different fates of DBTRG-05 and U87-MG cells, respectively. Some lines of evidence suggested that, in the pres- 
Table 2: Genes down-regulated following CPT treatment in both U87-MG and DBTRG-05

\begin{tabular}{ll}
\hline GeneName & Description \\
\hline & DNA metabolism and replication \\
ADK & Adenosine kinase \\
CDC45L & Cell division cycle 45 like \\
DTYMK & Deoxythymidylate kinase (dTMP kinase) \\
FENI & Flap structure specific endonuclease I \\
H2AFZ & H2A histone family Z \\
KIAA0I0I & The PCNA-associated factor KIAA0 I0I/p I5(PAF) \\
MCM2 & Mini chromosome maintenance deficient 2 \\
MCM3 & Minichromosome maintenance deficient 3 \\
MCM7 & Minichromosome maintenance deficient 7 \\
RRMI & Ribonucleotide reductase MI subunit, \\
RRM2 & Ribonucleotide reductase subunit M2, \\
TYMS & Thymidylate synthetase \\
UHRFI & Nuclear protein 95 \\
& Cell cycle and mitosis \\
ANKT & nucleolar and spindle associated protein I \\
BIRC5 & Survivin \\
CCNA2 & Cyclin A2 \\
CDC2 & Cell division cycle 2 \\
CDCA5 & cell division cycle associated 5 \\
KNSL6 & Mitotic centromere-associated kinesin (kinesin-like 6) \\
PRCI & Protein regulator of cytokinesis I \\
STMNI & Stathmin I (oncoprotein I8) \\
TOPK & PDZ-binding kinase \\
UBE2C & Ubiquitin-conjugating enzyme E2C \\
ZWINT & ZWI0 interactor \\
& Miscellaneous \\
DKFZP762EI3I2 & Protein of unknown function \\
I_932099 & Protein with high similarity to human HNRPAI, \\
IDI & Inhibitor of DNA binding I \\
KPNA2 & Karyopherin alpha 2 (importin alpha I), \\
LOXL2 & Lysyl oxidase-like 2 \\
PI00 & EBNA-2 co-activator (I00 kD) \\
SPOCK & Testican \\
TSSC3 & Tumor suppressing subtransferable candidate 3 \\
UBE2T & ubiquitin-conjugating enzyme E2T \\
&
\end{tabular}

ence of wild-type p53 and low CPT doses, cells mainly develop a senescence-like phenotype whereas undergo apoptosis, if p53 is mutated [5]. Taking into account that

A

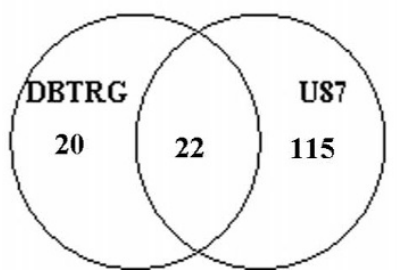

Figure 4

Venn-diagram representation of gene transcripts up(A) and down-regulated (B) by CPT in either/both U87-MG and DBTRG-05 cell lines. the two glioblastoma cell lines we used are both wild type for p53 [26], we suggested that the mutational status of p53 is not sufficient by itself to predict the CPT effects in our cell model. The difference in p21 protein stability between U87-MG and DBTRG-05 cells, already described by $\mathrm{Li}$ and coworkers [26], probably plays a more important role than the mutational status of p53 in the determination of the cell fate, senescence versus apoptosis. This results, moreover, agrees with the data reported for p53 wild-type HCT166 colon carcinoma cells, in which the ability of low doses of CPT to induce senescence and actively inhibit apoptosis was correlated to the sustained expression of p21 [4].

The overall transcriptional response, activated through a 72-hours time-course treatment with CPT, reflected, in part, the divergent biological effects triggered by TopoI inhibition. In fact, the number of genes, whose expression was affected, was much higher in the cells undergoing senescence rather than apoptosis. In addition, the disproportion between down- and up-regulated genes suggested that the development of senescence was accompanied by a general inhibition of transcription, which seemed not to affect, in a similar manner, the apoptotic DBTRG-05 cell population. Interestingly "transcription from Pol II promoter" was, indeed, one of the biological process identified by EASE analysis as significantly enriched in the list of U87-MG down-regulated genes, where we found the repression of many transcription factors mRNAs such as AHR; CHD1; CNOT2; DEK; ELL2; EPAS1; ETV1; FOXC2; FOXM1; GLI3; GTF2F2; HIPK2; HIRA; ID1; MNAT1; MYC; NCOA6; NCOR1; NR2F2; PBX3; RB1; RBBP8; SMARCA5; TCF4; TFDP1 and TRIP13.

In spite of the difference in the transcriptional profiles of the two cell lines, the general picture of the biological processes, returned by High-Troughput GoMINER and expressed in terms of GO categories, that resulted as mostly affected along the exposure time, highlighted the similarities between the two data-sets. This could arise from a general response to genotoxic stress induced by CPT, independently from the fate followed by the damaged cells (senescence or apoptosis). In fact, $60 \%$ of the genes, that were modulated in apoptotic DBTRG-05 cells, were regulated in senescent U87-MG cells, as well, and, within this list, many genes were described to be induced by DNA damage, as transcriptional targets of wild-type p53, including: p21/waf1, GADD45A, ATF3, PIG3, P53CSV, FDXR, DDIT3, KFL5 and BIRC5 [27]. In particular, a recent report has shown that BIRC5 (survivin), which inhibits apoptosis and controls cell division [28], was up-regulated in many brain cancers [29] but repressed both in vitro and in vivo, following TopoI inhibition in myeloid leukemia cells [15]. Noteworthy, regardless of the outcome due to CPT treatment, BIRC5 was down-reg- 

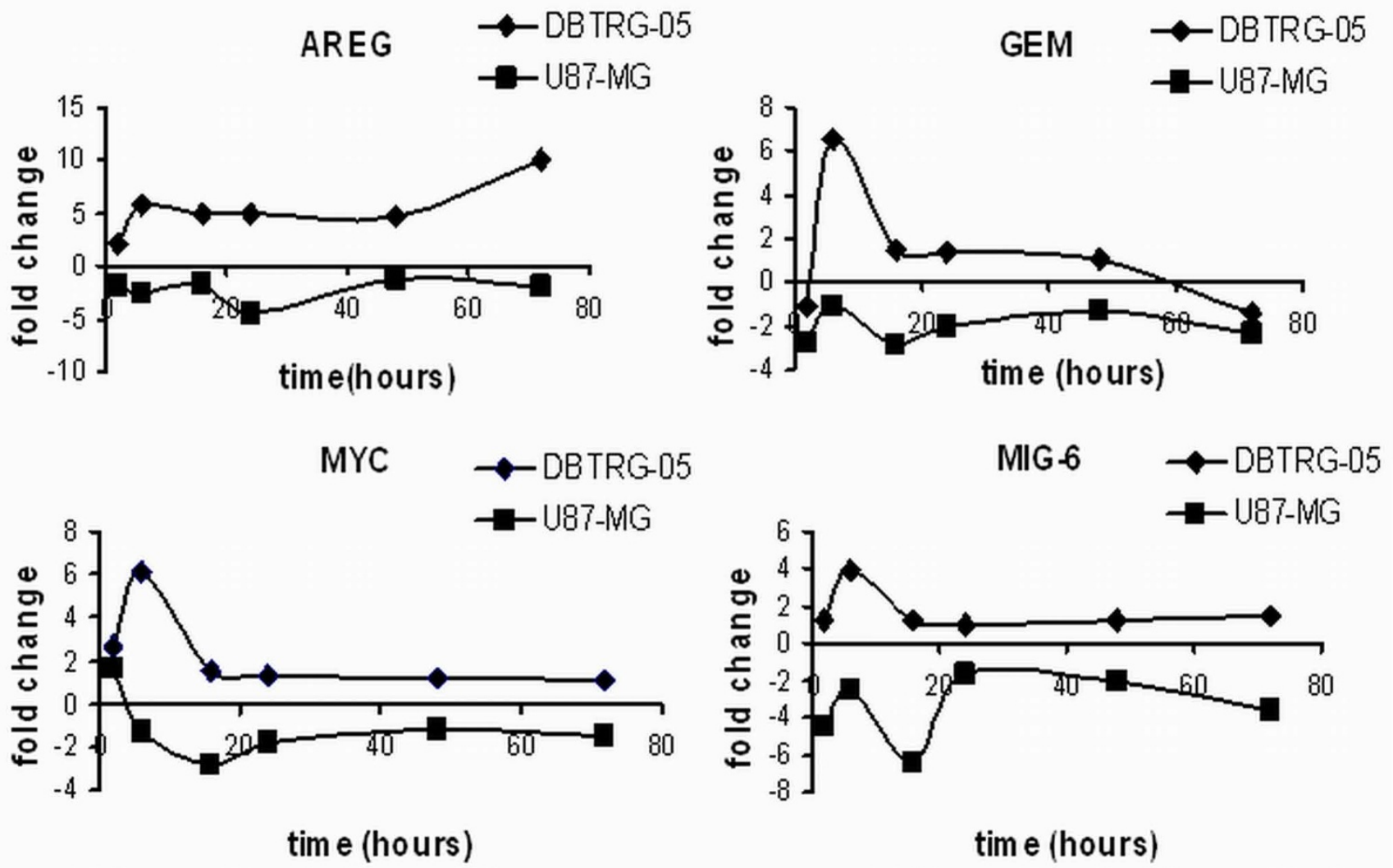

Figure 5

Time-dependent expression profile of AREG, GEM, MYC and MIG6. $\log _{2}$ (expression ratio) was plotted versus time.

ulated both in U87-MG and DBTRG-05 cells, confirming the relevance of this transcriptional target in the action of this drug agent.

Most of the common repressed genes were involved in DNA replication, mitosis and spindle organization. The delayed expression of mitosis related genes was already described in HCT116 non-apoptotic colon cancer cells, treated with CPT [13], and this modulation was reported as a common hallmark of the transcriptional effect induced by the activation of the DNA damage G2-checkpoint [30]. However, as highlighted by High-Throughput GoMINER and EASE functional analysis, the mitotic down-regulation induced by CPT was much more evident in senescent U87-MG cells where, in particular, the inhibition of several cyclins D1, E1, A2, B1 and B2, was accompanied by the ipo-expression of genes belonging to the mitotic spindle checkpoint pathway, such as MAD2, BUB1 and BUB3. The spindle checkpoint function monitors the completion of the spindle-kinetochore attachment and is a crucial factor to ensure the accurate sister chromatid segregation during cell division. In agreement with spindle checkpoint dysfunction, we, indeed, observed a slight increase of aneuploidy in U87-MG cells at the latest time point. Our observation is consistent with previous reports demonstrating that the down-regulation of spindle checkpoint proteins preceded the induction of senescence in human hepatoma cells exposed to a low dose of doxorubicin [6] and that normal human diploid fibroblasts underwent premature senescence in culture when BUB 1 was silenced by RNAi [31]. Taken together with other data, demonstrating that spindle checkpoint compromised HCT116-MAD2+/-cells, efficiently escaped from TopoI poison-induced apoptosis [32] and that MAD2-silenced gastric cancer SGC7901 cells increased the resistance to DNA damaging agents by up-regulating Bcl2 [33], it is reasonable to speculate that the induction of senescence and the inhibition of apoptosis might be linked to the ipo-expression of spindle checkpoint proteins and that these proteins might also modulate the sensibility to DNA damaging agents, such as TopoI inhibitors.

In U87-MG but not in apoptotic DBTRG-05 cells, CPT treatment also led to the down-regulation of TFDP1 (DRTF1 polypeptyde 1, DP1), a transcription factor that 
NT 2 h 6 h $\quad 16 h \quad 24 h \quad 72 h$
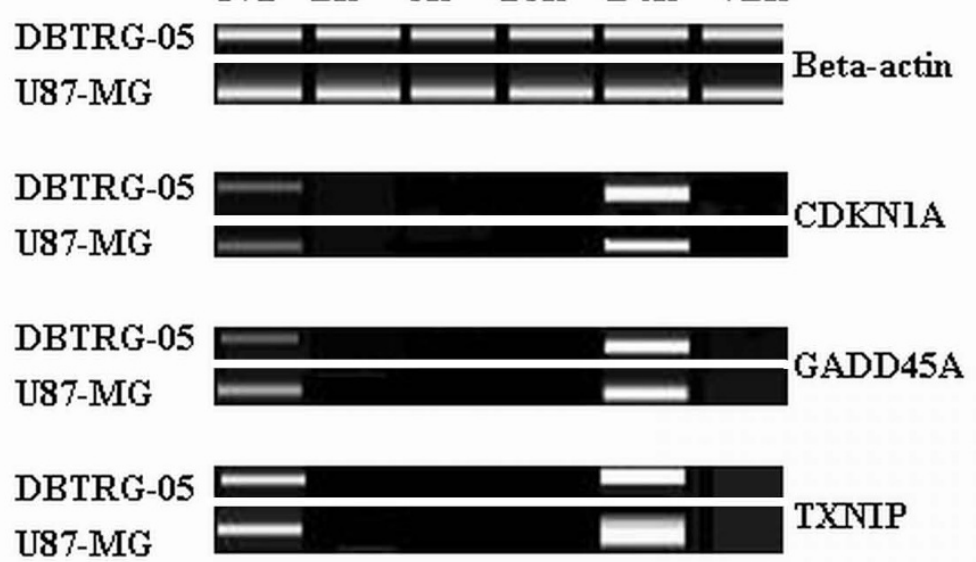

\begin{tabular}{lcc}
\hline & \multicolumn{2}{c}{ LA7-MG } \\
\hline \hline & $\begin{array}{c}\text { RT-PCR } \\
\text { Fold change }\end{array}$ & $\begin{array}{c}\text { Microarray } \\
\text { Fold change }\end{array}$ \\
CDKN1A 24h & 6.9 & 4.87 \\
GADD45 24h & 4.1 & 4.69 \\
TXNIP 24h & 13 & 16.9 \\
MYC 16h & -5.6 & -2.8 \\
GEM 6h & -1.82 & -2.8 \\
EREG 72h & 0.86 & 1.09 \\
AREG 24h & 1.4 & -4.46 \\
AREG 72h & -1.73 & -1.95 \\
\hline
\end{tabular}
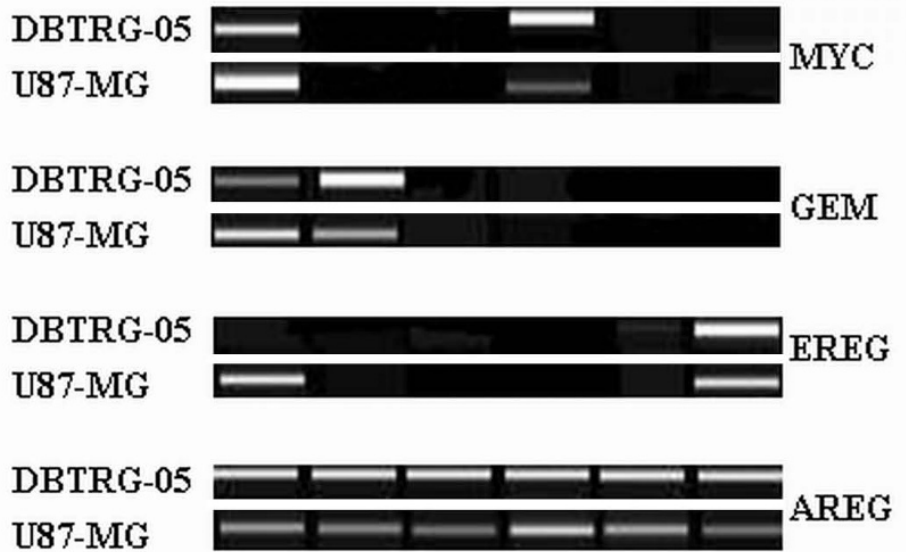

\begin{tabular}{lcc}
\hline & \multicolumn{2}{c}{ DETRG-05 } \\
\hline \hline & $\begin{array}{c}\text { RT-PGR } \\
\text { Fold change }\end{array}$ & $\begin{array}{c}\text { Merormy } \\
\text { Fold change }\end{array}$ \\
CDKN1A 24h & 10.9 & 4.92 \\
GADD45 24h & 4 & 5.61 \\
TXNIP 24h & 3.94 & 1.84 \\
MYC 16h & 1.8 & 1.60 \\
GEM 6h & 5.19 & 6.49 \\
EREG 72h & 23.4 & NA \\
AREG 16h & 4.56 & 4.9 \\
AREG 72h & 4.3 & 10.11 \\
\hline
\end{tabular}

Figure 6

Semi-quantitative RT-PCR post-validation of microarray results. A. Gene expression changes for seven genes (CDKNIA, GADD45, TXNIP, MYC, GEM, AREG, EREG) were measured at selected time points after CPT treatment by semi-quantitative RT-PCR and normalized to $\beta$-actin expression of time- and dose- matched controls. The RT-PCR reactions were analyzed with the DNAI000 kit of the Agilent 2100 Bioanalyzer to give a gel-like image. B. At each selected time point after CPT treatment, expression fold change values obtained with semi-quantitative RT-PCR and microarrays were compared.

plays a crucial role in cell cycle control, by forming a complex with the E2Fs proteins family [34]. The depletion of DP1 protein was recently reported to efficiently block E2F transcriptional activity and trigger a senescence-like cell cycle arrest [35]. Many of the genes involved in DNA replication and mitosis that were down-regulated in U87-MG cells are indeed known as E2F target genes (TK1, RRM1, RRM2, MCM3, MCM7, TOP2A, FEN1, RAD51, CDC2, CyclinA2, CyclinB1, CyclinB2, BUB1, HMG2, Stathmin, AnnexinVIII, Ki-67, RB etc) [36], suggesting a relevant role of this pathway in the development of a senescent phenotype in U87-MG cells.

Among the genes that showed a different CPT-timedependent profile in the two cell lines, MYC was, by far, the most important one, being involved in the regulation of fundamental biological processes, such as apoptosis and cell growth. In agreement with our evidence of MYC induction in DBTRG-05 apoptotic cells, the over-expression of MYC was already described to sensitize colon cancer cells to CPT-induced apoptosis [38] and to be necessary, in rat fibroblasts, for DNA damage-initiated apoptosis in the G2 phase of the cell cycle [39]. On the other hand, the down-regulation of MYC in U87-MG cells, fits the result of a recently published paper where the suppression of MYC oncogene triggers cellular senescence, in diverse tumor types including hepatocellular carcinoma, osteosarcoma and lymphoma [40].

In a previous paper [19], we have already reported the transcriptional profile of a CPT-resistant sub-line U87CPT-R, selected through repeated cycles of high dose 
Table 3: List of genes belonging to some of the most significantly down-regulated GO categories as resulted by GoMiner Hightroughput analysis

\begin{tabular}{|c|c|c|c|c|c|}
\hline \multicolumn{2}{|c|}{ Cell Cycle } & \multicolumn{2}{|c|}{ DNA metabolism } & \multicolumn{2}{|c|}{ M-Phase } \\
\hline U87 & DBTRG & U87 & DBTRG & U87 & DBTRG \\
\hline CDC45L & MCM7 & CDC6 & UBE2C & РОTI & MCM7 \\
\hline MCM3 & CDC45L & $\mathrm{PRCl}$ & CDC2 & CDC45L & CDC45L \\
\hline $\mathrm{PRCl}$ & MCM3 & BUBI & STMNI & MCM3 & RRM2 \\
\hline TFDPI & $\mathrm{PRCl}$ & MAD2LI & $\mathrm{PRCl}$ & FENI & MCM3 \\
\hline CKS2 & TOPK & TOPK & KPNA2 & PRIM2A & KPNA2 \\
\hline MAD2LI & UHRFI & CCNA2 & TOPK & $\mathrm{EZH} 2$ & FENI \\
\hline EXTI & CCNA2 & KNSL5 & CCNA2 & USPI & UHRFI \\
\hline $\mathrm{CCNB} 2$ & CDC2 & UBE2C & & RFC3 & DTYMK \\
\hline CDKN2D & UBE2C & CCNB2 & & RAD54B & RRMI \\
\hline RAD54B & ZWINT & $\mathrm{CDC} 2$ & & TOP2A & TYMS \\
\hline BIRC5 & STMNI & STMNI & & MCM6 & MCM2 \\
\hline MCM6 & KPNA2 & KPNA2 & & TYMS & \\
\hline TTK & BIRC5 & PKMYTI & & NFIB & \\
\hline CDKN3 & DTYMK & RAD54B & & MIDI & \\
\hline TOPBPI & MCM2 & CCNBI & & TOPBPI & \\
\hline CDC6 & & TTK & & CDC6 & \\
\hline MCM7 & & SMC2LI & & PRKDC & \\
\hline MNATI & & & & MCM7 & \\
\hline DLGI & & & & MNATI & \\
\hline BUBI & & & & RFC5 & \\
\hline UHRFI & & & & UHRFI & \\
\hline NOTCH2 & & & & RRMI & \\
\hline TOPK & & & & HMGI & \\
\hline CCNA2 & & & & RRM2 & \\
\hline KNSL5 & & & & NT5E & \\
\hline $\mathrm{CDC2}$ & & & & KPNA2 & \\
\hline UBE2C & & & & $\mathrm{MSH} 2$ & \\
\hline BARDI & & & & HMG2 & \\
\hline ZWINT & & & & DTYMK & \\
\hline CKSI & & & & MCM2 & \\
\hline \multicolumn{6}{|l|}{ MKI67 } \\
\hline \multicolumn{6}{|l|}{ STMNI } \\
\hline \multicolumn{6}{|l|}{$\mathrm{MSH} 2$} \\
\hline \multicolumn{6}{|l|}{ KPNA2 } \\
\hline \multicolumn{6}{|l|}{ PKMYTI } \\
\hline \multicolumn{6}{|l|}{ CCNBI } \\
\hline \multicolumn{6}{|l|}{$\mathrm{RBI}$} \\
\hline \multicolumn{6}{|l|}{ DTYMK } \\
\hline \multicolumn{6}{|l|}{ CCNE2 } \\
\hline \multicolumn{6}{|l|}{ MCM2 } \\
\hline SMC2LI & & & & & \\
\hline
\end{tabular}

$(15 \mu \mathrm{M})$ CPT treatments, and we demonstrated that these cells over-produced IL-1beta, as well as other pro-inflammatory cytokines. We also found IL1-beta induction in senescent U87-MG cells obtained after three months of continuous culturing with gradually increasing of CPT concentrations (from $1 \mathrm{nM}$ to $100 \mathrm{nM}$ ), thus demonstrating that the transcriptional induction of IL-1beta was a common hallmark of prolonged CPT treatment. In the present time-course study, the "late" (after 48h-treatment) induction of IL-1beta by CPT, together with other proteins known to be involved in regulation of immune response and/or response to stress, was confirmed in U87-MG cells but not in the apoptotic DBTRG-05 cell line. This data suggest that the positive modulation of this cytokine might have a strict correlation with the development and maintenance of a senescent phenotype.

This hypothesis is strengthened not only by the general consideration that the inflammatory response accompanies the aging process [41] but also by the finding that the transcriptional analysis of senescent fibroblasts showed the up-regulation of IL-1beta mRNA [42].

To demonstrate a direct link between IL-1beta and the phenotype observed in CPT- treated U87-MG cells, we used a gene silencing approach. The results showed that, in spite of an efficient knocking down of the IL-1beta expression, silenced U87-MG still developed senescence, after a $72 \mathrm{~h}$ CPT-treatment, thus suggesting that IL-1beta had only a marginal role in senescence development and maintenance.

This observation raises the question about the real significance that IL-1beta over-production and the following burst in inflammatory response might have, mostly in relation to prolonged treatment with TopoI inhibitors. In fact the persistent production of pro-inflammatory cytokines by senescent cells, that remain metabolically active at tumor site, might actually reduce the efficacy of СРT. It is, indeed, well accepted that inflammation had a great impact on the stimulation of tumor-growth, invasiveness and angiogenesis [43] and that the over-expression of IL-1beta by the tumor microenvironment favors the process of carcinogenesis and strengthens invasiveness of already existing malignant cells $[44,45]$, thus clearly influencing the outcome of anticancer therapy.

\section{Conclusion}

Our data provided new insight into the transcriptional response programs induced by CPT in a cell-culture based glioblastoma model and showed that, besides a great difference in the effector program triggered by CPT (senescence vs. apoptosis), we can detect a common transcriptional signature representative of the early cellular response to CPT-induced genotoxic stress. Nevertheless, we observed that several gene expression changes account for the divergent biological effects induced by CPT, in our model. The down-regulation of MAD2, BUB1 and BUB3 mitotic spindle checkpoint proteins together with the repression of the transcription factors DP1 and MYC were suggested as key elements in the regulation of drug-mediated senescence in U87-MG cells. In addition, by analyzing the role of IL-beta 1 up-regulation in senescent cells, we opened new insights into the importance 
Table 4: List of the biological processes as defined by the Gene Ontology that resulted enriched in the list of up-redulated and downregulated genes in U87-MG and DBTRG-05 by EASE analysis (EASE score, Bonferroni < 0.05 )

\begin{tabular}{|c|c|}
\hline U87 DOWN & DBTRG DOWN \\
\hline Cell cycle & Mitotic cell cycle \\
\hline Mitotic cell cycle & Cell cycle \\
\hline Cell proliferation & Cell proliferation \\
\hline Cell growth and maintenance & DNA metabolism \\
\hline Cellular process & Deoxyribonucleic acid metabolism \\
\hline \multicolumn{2}{|l|}{ DNA replication and chromosome cycle } \\
\hline \multicolumn{2}{|l|}{ DNA replication } \\
\hline \multicolumn{2}{|l|}{ S-phase of mitotic cell cycle } \\
\hline \multicolumn{2}{|l|}{ Mitosis } \\
\hline \multicolumn{2}{|l|}{ M-phase of mitotic cell cycle } \\
\hline \multicolumn{2}{|l|}{ DNA metabolism } \\
\hline \multicolumn{2}{|l|}{ DNA dependent DNA replication } \\
\hline \multicolumn{2}{|l|}{ Cell cycle checkpoints } \\
\hline \multicolumn{2}{|l|}{ M-phase } \\
\hline \multirow{2}{*}{\multicolumn{2}{|c|}{ Nuclear division }} \\
\hline & \\
\hline U87 UP & DBTRG UP \\
\hline Negative regulation of cell proliferation & N.A. \\
\hline \multicolumn{2}{|l|}{ Regulation of cellular process } \\
\hline \multicolumn{2}{|l|}{ Regulation of biological process } \\
\hline \multicolumn{2}{|l|}{ Regulation of cell proliferation } \\
\hline \multicolumn{2}{|l|}{ Response to external stimulus } \\
\hline \multicolumn{2}{|l|}{ Cell proliferation } \\
\hline Response to stress & \\
\hline
\end{tabular}

that inflammation might have in the determination of chemotherapy outcome.

In conclusion, our transcriptional analysis contributes to the search for potential biomarkers of CPT response in glioblastoma cells and add information to define the outcome of anticancer therapy in this model system.

\section{Methods}

\section{Cell lines}

U87-MG and DBTRG-05 glioblastoma cell lines were purchased from the American Type Culture Collection (Manassas, VA), and grown in a humidified atmosphere of $5 \%$ $\mathrm{CO}_{2}$ at $37^{\circ} \mathrm{C}$ in MEM culture medium (Invitrogen, Carlsbad, CA) supplemented with 10\% Fetal Bovine Serum, $2 \mathrm{mM}$ L-glutamine, $1 \mathrm{mM}$ sodium pyruvate, 17.8 $\mathrm{mM}$ sodium bicarbonate, $0.1 \mathrm{mM}$ non-essential aminoacids and in RPMI culture medium supplemented with $10 \%$ Fetal Bovine Serum and $2 \mathrm{mM}$ L-glutamine (Invitrogen, Carlsbad, CA), respectively. S-(+)-camptothecin was purchased from Sigma (St. Louis, MO) and dissolved to a concentration of $3 \mathrm{mM}$ in DMSO.

\section{Acute cytotoxicity assay}

The concentration of CPT that induced 50\% inhibition of cell growth $\left(\mathrm{GI}_{50}\right)$ was determined by staining cells with crystal violet according to the protocol described previ- ously (19). Cells were seeded at $2 \times 10^{5}$ cells per plate, in $60 \mathrm{~mm} \varnothing$ plates, allowed to attach for $24 \mathrm{~h}$ and subsequently exposed to CPT. One plate in triplicate was fixed before CPT treatment in order to measure the cell population at the time of drug addition (Tz). The GI50 was calculated according to the protocol used in the "In vitro Anticancer Discovery screen program" of the National Cancer Institute http://dtp.nci.nih.gov/branches/btb/ ivclsp.html.

\section{Annexin-V apoptosis assay}

To evaluate the percentage of apoptotic and necrotic cells, after a $24 \mathrm{~h}$ treatment with CPT, $5 \times 10^{4}$ cells were detached from the plates and incubated with $50 \mu \mathrm{l}$ of labeling solution containing Annexin-V-FLUOS reagent (Roche Diagnostics GmbH, Mannheim, Germany) diluted in Hepes buffer and $1 \mu \mathrm{g} / \mathrm{ml}$ propidium iodide (Sigma), for 10-15 minutes at room temperature. The cells were then counted under fluorescence.

\section{BrdU labeling and Flow cytometric analysis}

Adherent cells were pulsed with $30 \mu \mathrm{M}$ BrdU (Sigma) for $30 \mathrm{~min}$. at $37^{\circ} \mathrm{C}$. After two washing steps with $1 \%$ BSA/ PBS cells were fixed in $5 \mathrm{ml} \mathrm{70 \%} \mathrm{ethanol} \mathrm{for} 30 \mathrm{~min}$ and then centrifuged at $1500 \times \mathrm{g}$ for $10 \mathrm{~min}$. Single stranded DNA was produced by incubating fixed cells with $2 \mathrm{~N} \mathrm{HCl} /$ Triton X100 for $30 \mathrm{~min}$ at room temperature. After two 

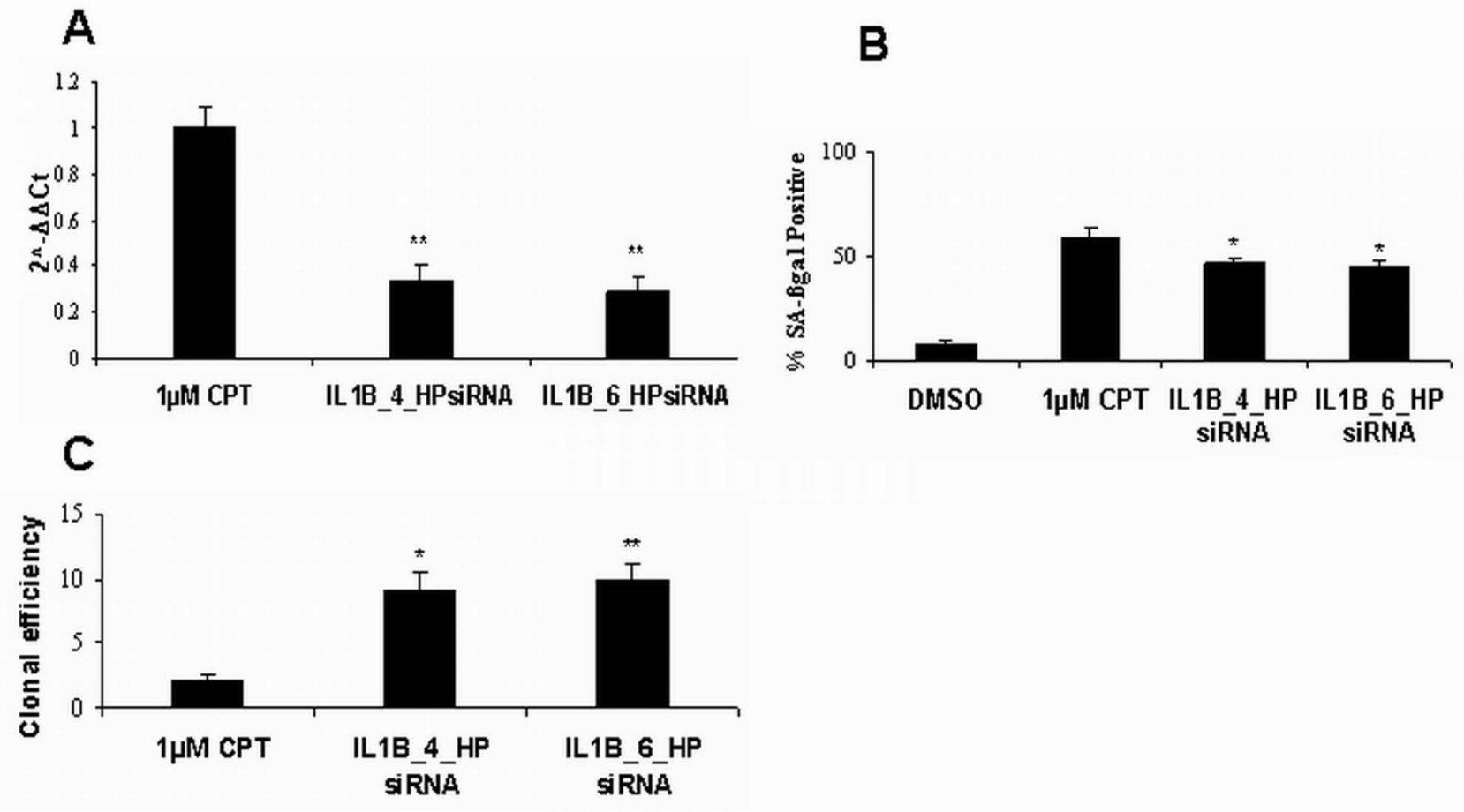

Figure 7

Effects of IL-I beta gene silencing on CPT-induced senescence in U87-MG cells. A. Real- time analysis of IL-Ibeta gene silencing. IL-I beta mRNA levels were significantly reduced (** $p<0.0$ I, Student's t-test) with respect to mRNA level of the non silenced CPT-treated cells. ILI-B relative expression was obtained by performing the comparative method [48]. Firstly, data were normalized to GAPDH, then to a calibrator, consisting of mRNA obtained from CPT treated cells. The results were expressed as $2^{\wedge-\Delta \Delta C \mathrm{t}}$, where $\Delta \mathrm{Ct}$ of each sample was defined as $\mathrm{Ct}_{\text {(target gene }=\mathrm{ILI} \text {-beta) }}-\mathrm{Ct}_{\mathrm{GAPDH}}$, and $\Delta \Delta \mathrm{Ct}=\Delta \mathrm{Ct}_{\text {(sample }=\mathrm{cDNA} \text { from }}$

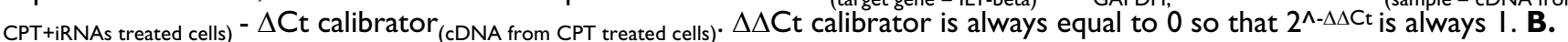
SA- $\beta$ gal activity, in response to I $\mu$ M CPT, was quantified in U87-MG cells in the presence or in the absence of IL-Ibeta gene silencing. DMSO, solvent control. Bars, standard error. ${ }^{*} p<0.05$, Student's t-test. C. 250 cells from either CPT and solvent exposed cells or IL-Ibeta-silenced/CPT-treated U87-MG cells were sub-cultured in fresh medium in five replicates. Cells were maintained in culture for 10 days, with bi-weekly medium changes, then were fixed with methanol, stained with $10 \%$ aqueous Giemsa and scored for colony formation. Only colonies containing more than 50 cells were counted. Clonal efficiency was calculated as the mean number of colonies per plate with respect to the solvent. Bars, standard error. ${ }^{*} p<0.05$, Student's t-test. ** $p<0.0$ I, Student's t-test.

washing steps, $10^{6}$ cells were re-suspended in $1 \mathrm{ml}$ of $0.5 \%$ Tween $20 / 1 \%$ BSA/PBS and incubated with $20 \mu \mathrm{l}$ of Anti-BrdU FITC (Becton Dickinson, San Josè, CA) for 30 min at room temperature. Washed cells were then re-suspended in $1 \mathrm{ml}$ of PBS containing $50 \mu \mathrm{g} / \mathrm{ml}$ propidium iodide. The analysis of DNA content and cell cycle were performed using a FACSCalibur equipped with $488 \mathrm{~nm}$ laser (Becton Dickinson, San Jose, CA, USA) and Cells Quest software (10.000 cells analyzed for each sample).

\section{SA- $\beta$-Gal staining}

To detect senescence - associated - $\beta$-galactosidase (SA- $\beta$ gal) activity, cells were washed twice in PBS and fixed in a buffer containing 2\% formaldehyde and $0.2 \%$ glutaraldehyde in PBS for $5 \mathrm{~min}$. at room temperature (Sigma). SA$\beta$-gal staining was then performed using a citric acid/ phosphate buffer (pH 6.00) containing $1 \mathrm{mg} / \mathrm{ml}$ of X-Gal,
$5 \mathrm{mM}$ potassium ferricyanide, $5 \mathrm{mM}$ potassium ferrocyanide, $2 \mathrm{mM} \mathrm{MgCl}_{2}$ and $150 \mathrm{mM} \mathrm{NaCl}$ (Sigma). A blue color was visible in senescent cells within $2 \mathrm{~h}$ but reached the maximum between 12 to $16 \mathrm{~h}$. At that time, counts were made on three random fields of about 100 cells.

\section{RNA preparation and hybridization}

Total RNA was isolated from exponentially growing cells using TRIzol Reagent (Life Technologies, Carlsbad, CA) and purified on Rneasy ${ }^{\mathrm{R}}$ affinity column (Qiagen, Valencia, CA). The quality of RNA was assessed with the Agilent bioanalyzer 2100 using the RNA nano kit (Agilent Technologies, Palo Alto, CA). cDNA was synthesised from 20 $\mu \mathrm{g}$ of total RNA and labelled with Cy3-dCTP or Cy5-dCTP (Perkin-Elmer, Boston, MA) following in details the manufacturer protocol (Agilent fluorescent direct label kit, G2555-98003, version 2.1. available online at http:// 
www.chem.agilent.com), optimized for use with Agilent oligo-microarray Kit. Labelled cDNA from the two reactions was combined, purified with QIAquick spin column (Qiagen), and then applied to the oligonucleotide slide (Human1A oligo microarray, G4110A) according to the Agilent 60-mer oligo microarray processing protocol (G4140-90010 version 7.1. available online at http:// www.chem.agilent.com). Slides were scanned in both Cy3 and Cy-5 channels with Agilent dual laser microarray scanner (G2565AA). Scanned images were analyzed by the Agilent Feature Extraction software 7.5 to derive the raw intensity data used in the next steps of analysis. The raw data discussed in this publication have been deposited in Arrayexpress, the EBI microarray data public repository (Arrayexpress http://www.ebi.ac.uk/arrayexpress/). The U87-MG has been assigned the accession number: EMEXP-741. The DBTRG- has been assigned the accession number: E-MEXP-751.

\section{Experimental design and microarray data analysis}

For each cell line we adopted an experimental design consisting of six after-treatment time points $(2 \mathrm{~h}, 6 \mathrm{~h}, 16 \mathrm{~h}, 24$ $\mathrm{h}, 48 \mathrm{~h}, 72 \mathrm{~h}$ ) compared to an untreated zero-time common reference. Total RNA samples, corresponding to each time point, were derived from a pool of RNAs extracted from three independent experiments. Each time point was replicated by performing a dye-swap. The data-sets of the two time-series experiment underwent preliminary data filtering procedures. Data, corresponding to features flagged as controls, were filtered out before proceeding to the following analysis. Filtered raw (median green and red signal) intensity (17874 features for the "U87_CPT" and 17905 features for the "DBTRG_CPT") were then $\log _{2^{-}}$ tranformed and normalized intra-array for intensity- and position-dependent bias using the Joint-LOWESS algorithm.

To assess differentially expressed genes, the transformed data were analyzed by using MAANOVA (Micro Array ANalysis Of VAriance) data analysis package of $\mathrm{R}$ programming environments [23]. The fixed-effect linear ANOVA model, $\gamma_{\mathrm{ijkg}}=\mu+A_{i}+D_{j}+T_{k}+G_{g}+A G_{i g}+D G_{i g}+$ $T G_{k g}+\varepsilon_{i j k g}$ was chosen to fit transformed intensity data $y$, where $\mu$ is the overall mean expression level and $\varepsilon_{i j k g}$ is the residual measurement effect. This model allows you to take into account the different sources of variance of an experiment due to array $(A)$, dye $(D)$, gene $(G)$, time points $(T)$ and to their combined effects $(A G, D G$ and $T G)$. The term $T G$ is that of primary interest in our analysis; it captures variations in the expression levels of a gene across the time points.

We then tested a null hypothesis of no differential expression (so that all TG values are equal to zero) using F statistics computed on the James-Stein shrinkage estimates of the error variance [46]. To avoid any assumption on error distribution, the package offers the possibility of computing p-values for hypothesis tests via permutation methods (in our analyzes 1000 permutations with sample shuffling were carried out). Finally the false-discovery rate controlling method [47] was used to correct significance estimate for multiple testing hypothesis. In the analysis of the "U87_CPT" we selected, as differentially expressed, the features with $\mathrm{p}<0.01$ in the $\mathrm{F}$ test, after false-discovery rate adjustment, while in the analysis of the "DBTRG_CPT", the chosen threshold p-value was 0.05 . Therefore, 3168 and 155 genes were deemed as significantly modulated in the "U87_CPT" and the "DBTRG_CPT" analysis, respectively.

\section{High-throughput GoMiner and EASE analysis of microarray data}

High-throughput GoMiner, calculates for each category the enrichment factor $\operatorname{Re}=(\mathrm{nf} / \mathrm{n}) /(\mathrm{Nf} / \mathrm{N})$, where $\mathrm{nf}$ is the number of flagged genes within the category (i.e., genes whose expression levels are considered to be changed beyond a given threshold), $\mathrm{n}$ is the total number of genes within that same category, $\mathrm{Nf}$ is the number of flagged genes on the entire microarray, and $\mathrm{N}$ is the total number of genes on the microarray. For each category a Fisher's exact p-values (for the one-tailed test) was calculated to measure its statistical significance. Furthermore to address the question of multiple comparisons the program also estimates the False discovery rate (FDR) by using a re-sampling algorithm.

EASE first calculates the List Hits (number of genes in the gene list that belong to the Gene Category), the List Total (number of genes in the gene list), the Population Hits (number of genes in the total group of genes assayed that belong to the specific Gene Category) and the Population Total (number of genes in the total group of genes assayed that belong to any Gene category within the system). Then the probability of seeing the number of "List Hits" in the "List Total" given the frequency of "Population Hits" in the "Population Total" is calculated as the Fisher exact probability. EASE also calculate another metric known as the "EASE score" which is the upper bound of the distribution of Jackknife Fisher exact probabilities. The EASE score is a conservative adjustment of the Fisher exact that strongly penalizes the significance of categories supported by few genes. Moreover in order to address the multiple comparisons problem we used Bonferroni method to correct the EASE score.

\section{Semi-quantitative RT-PCR}

Some gene expression changes detected in the microarray were validated by semi-quantitative Rt-PCR. $1 \mu \mathrm{g}$ of total RNA was retro-transcribed to cDNA using 200 Units of SuperScript II RnaseH- Reverse Transcriptase (Life Technologies), with $25 \mu \mathrm{g} / \mathrm{ml}$ oligo(dT) primer and $500 \mu \mathrm{M}$ dNTP mix. 
PCR was performed with a reduced number of cycles, using less than $10 \%$ of the RT reaction, with 5 Units of Taq DNA polymerase (Life Technologies), $1.5 \mu \mathrm{M} \mathrm{MgCl} 2,200$ $\mu \mathrm{M}$ dNTP mix and $20 \mu \mathrm{M}$ forward/reverse primers for: IL$1 ß \quad$ (5'gggcctcaaggaaaagaatc3'/5'ttctgcttgagaggtgctga3'), EREG (5'cctggtgcacagtgcttaga $3 ' / 5$ 'actccccagggttagcttgt $\left.3^{\prime}\right)$, GEM (5'gggagagagtgggagtttcc $3 ' / 5$ 'aaagatgttggccagagtgg 3 '), MYC (5'ctcctggcaaaaggtcagag3'/5'ggcctttcattgtttcca3'), TXNIP (5'gccacacttaccttgccaat3'/5'ggaggagcttctggggtatc3'), AREG (5'tggattggacctcaatgaca3'/5'ccatttttgcctcccttttt3'), GADD45(5'ggaggaagtgctcagcaaag3' /

5 'tcccggcaaaaacaaataag3'),

CDKN1A (5'gacaccactggagggtgact3'/5'tggattagggcttcctcttgg 3')

(Sigma). Reactions were run on GeneAmp PCR System 9600 (Applied Biosystems Foster City, USA).

The amplified fragments were analyzed and quantified using the DNA1000 kit of the Agilent 2100 Bioanalyzer.

siRNA and quantitative real-time PCR

We used two different HP GenomeWide siRNA duplexes against IL-1beta (IL1B_4_HPsiRNA and IL1B_6_HPsiRNA, Qiagen). U87-MG cells were transfected with HiPerFect Trasfection Reagent (Qiagen) according to the manufacturer's protocol, using a final concentration of $10 \mathrm{nM}$ siRNA. The transfection efficiency was tested by a non-silencing control siRNA, labeled with Alexa Fluor 488 (Qiagen). Gene silencing was checked by real-time RT-PCR using the SYBR Green qPCR Supermix (Invitrogen) and two different forward/reverse primers for IL-1beta (a: 5'aacctcttcgaggcacaag3' 5'ctgtttagggccatcagctt3'; b: 5'gggcctcaaggaaaagaatc3'/ $5^{\prime}$ 'tctgcttgagaggtgctga3'), depending on the siRNA target sequence.

Total RNA was extracted using TriZol reagent and purified on RNeasy ${ }^{\mathrm{R}}$ mini affinity column kit (Qiagen), and cDNA was synthesized with the SuperScript ${ }^{\mathrm{tm}}$ III First-Strand Synthesis SuperMix (Invitrogen). The level of test cDNA relative to that of GAPDH was calculated by the $2^{-\Delta \Delta \mathrm{C}_{\mathrm{T}}}$ method. [46]

\section{Competing interests}

The authors declare that they have no competing interests.

\section{Authors' contributions}

EM planned and performed gene expression profiling laboratory work and data analysis, carried out siRNA experiments and prepared the draft version of the manuscript. CS planned and performed gene expression profiling laboratory work and data analysis, carried out siRNA experiments, and prepared the draft version of the manuscript.
DQ performed statistical analysis. GD was involved in the first steps of statistical data analysis, SP performed RT-PCR experimental validation. MC and GF participated in FACS analysis. MM carried out the cell culture treatments and cell viability assessments. WH and MV participated in the study design and in the scientific discussion. RS contributed to the conception of the study. AC performed the supervision and coordination of the study. PS participated in the supervision of the study and manuscript preparation.

All authors have read and approved the final version of the manuscript.

\section{Availability \& requirements http://discover.nci.nih.gov/gominer/htgm.jsp}

http://dtp.nci.nih.gov/branches/btb/ivclsp.html

http://www.chem.agilent.com

http://www.ebi.ac.uk/arrayexpress/

\section{Additional material}

\section{Additional file 1}

U87_datasets of differentially expressed genes. File contain the complete list of differentially expressed genes identified by MAANOVA. Click here for file

[http://www.biomedcentral.com/content/supplementary/14764598-7-66-S1.xls]

\section{Additional file 2}

DBTRG_datasets of differentially expressed genes. File contain the complete list of differentially expressed genes identified by MAANOVA. Click here for file

[http://www.biomedcentral.com/content/supplementary/14764598-7-66-S2.xls]

\section{Additional file 3}

GoMiner Hightroughput Functional analysis of up-regulated GO categories in either U87-MG and DBTRG-05. Clustered Image Maps (CIM) with hierarchically clustered (euclidean distance, avarage linkage clustering) up-regulated GO categories versus time. The scale corresponds to the following numerical transformation of the FDR (false discovery rate) value: $T-0.9^{*} F D R$, where $T$ is the chosen value of significance (in our analysis 0.05).

Click here for file

[http://www.biomedcentral.com/content/supplementary/14764598-7-66-S3.ppt] 


\section{Additional file 4}

GoMiner Hightroughput Functional analysis of down-regulated Go categories in U87-MG. Clustered Image Maps (CIM) with hierarchically clustered (euclidean distance, avarage linkage clustering) down-regulated GO categories versus time. The scale corresponds to the following numerical transformation of the FDR (false discovery rate) value: T-0.9*FDR, where $T$ is the chosen value of significance (in our analysis 0.05). Click here for file

[http://www.biomedcentral.com/content/supplementary/14764598-7-66-S4.ppt]

\section{Additional file 5}

GoMiner Hightroughput Functional analysis of down-regulated Go categories in DBTRG-05. Clustered Image Maps (CIM) with hierarchically clustered (euclidean distance, avarage linkage clustering) down-regulated GO categories versus time. The scale corresponds to the following numerical transformation of the FDR (false discovery rate) value: $T$ $0.9^{*} F D R$, where $T$ is the chosen value of significance (in our analysis $0.05)$.

Click here for file

[http://www.biomedcentral.com/content/supplementary/14764598-7-66-S5.ppt]

\section{Acknowledgements}

This work has been supported by the Italian Ministry for University and Research (MIUR) under grant FISR I509 (2002).

\section{References}

I. Hsiang YH, Lihou MG, Liu LF: Arrest of replication forks by drugstabilized topoisomerase I-DNA cleavable complexes as a mechanism of cell killing by camptothecin. Cancer Res 1989, 49:5077-5082.

2. Liu LF, Desai SD, LI T, Mao Y, Sun M, Sim S: Mechanism of action of camptothecin. Ann N Y Acad Sci 2000, 922: I-26.

3. Carson JP, Zhang N, Frampton GM, Gerry NP, Lenburg ME, Christman MF: Pharmacogenomic identification of targets for adjuvant therapy with the topoisomerase poison camptothecin. Cancer Res 2004, 64:2096-2 I04.

4. Han Z, Wei W, Dunaway S, Darnowski JW, Calabresi P, Sedivy J, Hendrickson EA, Balan KV, Pantazis P, Wyche $\mathrm{JH}$ : Role of p2I in Apoptosis and senescence of human colon cancer cells treated with camptothecin. J Biol Chem 2002, 277: I7154-17160.

5. Wang Y, Zhu S, Cloughesy TF, Liau LM, Mischel PS: p53 disruption profoundly alters the response of human glioblastoma cells to DNA topoisomerase I inhibition. Oncogene 2004, 23:1283-1290

6. Eom YW, Kim MA, Park SS, Goo MJ, Kwon HJ, Sohn S, Kim WH, Yoon G, Choi KS: Two distinctive modes of cell death induced by doxorubicin: apoptosis and cell death through mitotic catastrophe accompanied by senescence-like phenotype. Oncogene 2005, 24:4765-4777.

7. Zhou BB, Elledge SJ: The DNA damage response: putting checkpoints in perspective. Nature 2000, 408:433-439.

8. Ljungman M: Activation of DNA damage signaling. Mutat Res 2005, 577:203-216.

9. Flatten K, Dai NT, Vroman BT, Loegering D, Erlichman C, Karnitz LM, Kaufmann SH: The role of Checkpoint kinase I in sensitivity to topoisomerase I poisons. J Biol Chem 2005, 280(14): 14349-| 4355.

10. Huang TT, Wuezberger-Davis SM, Seuzer BJ, Shumway SD, Kurama T, Boothman DA, Miyamoto S: NF-kB activation by camptothecin: a linkage between nuclear DNA damage and cytoplasmic signaling events. J Biol Chem 2000, 275:950I-9509.

II. Janssens S, Tschopp J: Signals from within: the DNA-damageinduced NF-kappaB response. Cell Death Differ 2006, 13:773-784.
12. Amundson SA, Do KT, Vinikor L, Koch-Paiz CA, Bittner ML, Trent JM, Meltzer P, Fornace AJ Jr: Stress specific signatures: expression profiling of $\mathrm{p} 53$ wild-type and -null human cells. Oncogene 2005, 24:4572-4579.

13. Zhou Y, Gwadry FG, Reinhold WC, Miller LD, Smith LH, Scherf U, Liu ET, Kohn KW, Pommier Y, Weinstein JN: Transcriptional regulation of mitotic genes by camptothecin-induced DNA damage: Microarray analysis of dose- and time-dependent effects. Cancer Res 2002, 62:1688-1695.

14. Ullmannova V, Haskovec C: Gene expression during camptothecin-induced apoptosis in human myeloid leukemia cell line ML-2. Neoplasma 2004, 5 I: I75-180.

15. Minderman H, Conroy JM, O'Loughlin KL, McQuaid D, Quinn P, Li S, Pendyala L, Nowak NJ, Baer MR: In vitro and in vivo irinotecaninduced changes in expression profiles of cell cycle and apoptosis-associated genes in acute myeloid leukemia cells. Mol Cancer Ther 2005, 4:885-900.

16. Reinhold WC, Kouros-Mehr H, Kohn KW, Maunakea AK, Lababidi S, Roschke A, Stover K, Alexander J, Pantazis P, Miller L, Liu E, Kirsch IR, Urasaki Y, Pommier Y, Weinstein JN: Apoptotic susceptibility of cancer cells selected for camptothecin resistance: gene expression profiling, functional analysis, and molecular interaction mapping. Cancer Res 2003, 63:1000-10II.

17. Friedman HS, Keir ST, Houghton PJ: The emerging role of Irinotecan (CPTII) in the treatment of malignant glioma in brain tumours. Cancer 2003, 97:2359-2362.

18. Bent MJ Van den, Hegi ME, Stupp R: Recent developments in the use of chemotherapy in brain tumours. Eur J Cancer 2006, 42:582-588.

19. Morandi E, Zingaretti C, Chiozzotto D, Severini C, Semeria A, Horn W, Vaccari M, Serra R, Silingardi P, Colacci A: A cDNA-microarray analysis of camptothecin resistance in glioblastoma cell lines. Cancer Lett 2006, 23I:74-86.

20. Kahlem P, Dorken B, Schmitt CA: Cellular senescence in cancer treatment: friend or foe. J Clin Invest 2004, I I 3:169-174.

21. Campisi J: Senescent cells, tumor suppression, and organism aging: good citizens, bad neighbors. Cell 2005, 1 20:5 I3-522.

22. Roberson RS, Kussick S], Vallieres E, Chen S], Wu DY: Escape from therapy-induced accelerated cellular senescence in p53-null lung cancer cells and in human lung cancers. Cancer Res 2005, 65:2795-2803.

23. Wu H, Kerr K, Cui X, Churchill GA: MAANOVA: a software package for the analysis of spotted cDNA microarray experiments. In The analysis of gene expression data: methods and software Edited by: Parmigiani G, Garett ES, Irizarry RA, et al. Heidelberg: Springer; 2003:3|3-34|

24. Zeeberg BR, Qin H, Narasimhan S, Sunshine M, Cao H, Kane DW, Reimers M, Stephens RM, Bryant D, Burt SK, Elnekave E, Hari DM, Wynn TA, Cunningham-Rundles C, Stewart DM, Nelson D, Weinstein JN: High-Throughput GoMiner, an 'industrial-strength' integrative gene ontology tool for interpretation of multiplemicroarray experiments, with application to studies of Common Variable Immune Deficiency (CVID). BMC Bioinformatics 2005, 6: I- I8

25. Hosack DA, Glynn D Jr, Sherman BT, Lane HC, Lempicki RA: Identifying Biological Themes within Lists of Genes with EASE. Genome Biology 2003, 4:R70.

26. Li Y, Dowbenko D, Lasky LA: AKT/PKB phosphorylation of p2 I Cip/WAFI enhances protein stability of p2 ICip/WAF I and promotes cell survival. J Biol Chem 2002, 277: I 352-I I 36 I.

27. Kho PS, Wang Z, Zhuang L, Li Y, Chew JL, Ng HH, Liu ET, Yu Q: p53regulated transcriptional program associated with genotoxic stress-induced apoptosis. J Biol Chem 2004, 279:2 I I83-2II 92.

28. Fukuda S, Pelus LM: Survivin, a cancer target with an emerging role in normal adult tissues. Mol Cancer Ther 2006, 5: 1087-1098.

29. Xie D, Zeng YX, Wang HJ, Wen JM, Tao Y, Sham JS, Guan XY: Expression of cytoplasmic and nuclear Survivin in primary and secondary human glioblastoma. $\mathrm{Br} J$ Cancer 2006, 94:108-114

30. Crawfords DF, Piwnica-Worms H: The G2 DNA damage checkpoint delays expression of genes encoding mitotic regulators. J Biol Chem 200I, 276(40):37I66-37I77.

31. Gjoerup OV, Wu J, Chandler-Militello D, Williams GL, Zhao J, Schaffhausen B, Jat PS, Roberts TM: Surveillance mechanism linking Bubl loss to the p53 pathway. Proc Natl Acad Sci USA 2007, I 04:8334-8339. 
32. Vogel C, Kienitz A, Muller R, Bastians H: The mitotic spindle checkpoint is a critical determinant for topoisomerasebased chemotherapy. J Biol Chem 2005, 280:4025-4028.

33. Du Y, Yin F, Hu S, Wang J, Xie H, Hong L, Fan D: Depression of Mad2 inhibits apoptosis of gastric cancer cells by upregulating $\mathrm{Bcl}-2$ and interfering mitochondrion pathway. Biochem Biophys Res Commun 2006, 345:1092-1098.

34. Dyson N: The regulation of E2F by pRB-family proteins. Genes Dev 1998, I 2:2245-2262.

35. Maehara K, Yamakoshi K, Ohtani N, Kubo Y, Takahashi A, Arase S, Jones N, Hara E: Reduction of total E2F/DP activity induces senescence-like cell cycle arrest in cancer cells lacking functional pRB and p53. J Cell Biol 2005, 168:553-560.

36. Ishida S, Huang E, Zuzan H, Spang R, Leone G, West M, Nevins JR: Role for E2F in control of both DNA replication and mitotic functions as revealed from DNA microarray analysis. Mol Cell Biol 200I, 21:4684-4699.

37. Arango D, Mariadason JM, Wilson AJ, Yang W, Corner GA, Nicholas C, Aranes MJ, Augenlicht LH: c-Myc overexpression sensitises colon cancer cells to camptothecin-induced apoptosis. Brit J Cancer 2003, 89: I757-I765.

38. Adachi S, Obaya AJ, Han Z, Ramos-Desimone N, Wyche JH, Sedivy J: c-myc is necessary for DNA damage-induced apoptosis in the G2 phase of the cell cycle. Mol Cell Biol 200I, 21:4929-4937.

39. Guney I, Wu. S, Sedivy JM: Reduced c-Myc signaling triggers telomere-independent senescence by regulating $\mathrm{Bmi}-\mathrm{I}$ and pI 6INK4a. Proc Natl Acad Sci USA 2006, 103:3645-3650.

40. Wu CH, van Riggelen J, Yetil A, Fan AC, Bachereddy P, Felsher DW: Cellular senescence is an important mechanism of tumor regression upon c-myc inactivation. Proc Natl Acad Sci USA 2007, 104: | 3028-13033.

4I. Gee JR, Ding Q, Keller JN: Age-related alterations of Apolipoprotein $\mathrm{E}$ and Interleukin-I beta in the aging brain. Biogerontology 2006, 7:69-79.

42. Hardy K, Mansfield L, Mackay A, Benvenuti S, Ismail S, Arora P, O'Hare MJ, Jat PS: Transcriptional networks and cellular senescence in human mammary fibroblast. Mol Biol Cell 2005 16:943-953.

43. Coussens LM, Werb Z: Inflammation and cancer. Nature 2002, 420:860-867.

44. Krelin $\mathrm{Y}$, Voronov E, Dotan S, Elkabets M, Reich E, Fogel M, Huszar M, Iwakura Y, Segal S, Dinarello CA, Apte RN: Interleukin-I betadriven inflammation promotes the development and invasiveness of chemical carcinogen-induced tumors. Cancer Res 2007, 67: 1062-107|.

45. Apte RN, Krelin Y, Song X, Dotan S, Recih E, Elkabets M, Carmi Y, Dvorkin T, White RM, Gayvoronsky L, Segal S, Voronov E: Effects of micro-environment- and malignant cell-deriverd inteleukin$I$ in carcinogenesis, tumors invasiveness and tumors-host interactions. Eur J Cancer 2006, 42:75I-759.

46. Cui X, Hwang JT, Qiu J, Blades NJ, Churchill GA: Improved statistical tests for differential gene expression by shrinking variance components estimates. Biostatistics 2005, 6:59-75.

47. Benjamini $Y$, Hochberg $Y$ : Controlling the false discovery rate: a practical and powerful approach to multiple testing. J $R$ Statist Soc B 1995, 57:289-300.

48. Livak KJ, Schmittgen TD: Analysis of relative gene expression data using real-time quantitative PCR and the 2(-Delta Delta C(T)) Method. Methods 200I, 25:402-408.
Publish with Bio Med Central and every scientist can read your work free of charge

"BioMed Central will be the most significant development for disseminating the results of biomedical research in our lifetime. "

Sir Paul Nurse, Cancer Research UK

Your research papers will be:

- available free of charge to the entire biomedical community

- peer reviewed and published immediately upon acceptance

- cited in PubMed and archived on PubMed Central

- yours - you keep the copyright
BioMedcentral 